\title{
Approaches to Reduction in Treatments of Culture-Cognition Relations: Affordances and Limitations
}

\author{
Commentary on Gauvain and Munroe
}

Geoffrey B. Saxe

Graduate School of Education, University of California, Berkeley, Calif., USA

\author{
Key Words \\ Cognitive development $\cdot$ Cross-cultural psychology $\cdot$ Societal change
}

Gauvain and Munroe take on a provocative question when they ask: how is cultural change related to the cognitive development of individuals? To address the question, they report an ambitious project that contrasts the cognitive development of people from two small-scale traditional societies (in Kenya and Nepal) with those from two industrial societies (in American Samoa and Belize) [Gauvain \& Munroe, 2009]. The findings produced are consistent with other studies that have investigated similar questions in less targeted ways: individuals from more industrialized communities perform more successfully on IQ-like measures than individuals from small-scale traditional groups. Further, across communities children's performances on the IQ-like measures showed the expected correlations with variables associated with industrialization (like the adoption of radios in homes, the use of why? questions with children, and the reduction of open-fire cooking). The conclusion they draw is that, as small-scale traditional communities shift to industrial societies, individual members advance in cognitive development, and the authors point to their correlational analyses as ways of understanding mechanisms.

\section{Contention and Controversy}

The article reopens arenas of contention and controversy in prior research on culture-cognition relations, especially in the empirical project the authors describe. Some of the contentious issues are related to ways that the authors treat cultural

\begin{tabular}{ll}
\hline KARGER & ( ) 2012 S. Karger AG, Basel \\
0018-716X/12/0554-0233\$38.00/0 \\
$\begin{array}{ll}\text { Fax +41613061234 } \\
\text { www.karger.com }\end{array}$ & $\begin{array}{l}\text { Accessible online at: } \\
\text { www.karger.com/hde }\end{array}$
\end{tabular}

Geoffrey Saxe

Cognition and Development, Graduate School of Education, University of California 4315 Tolman Hall, Berkeley, CA 94720-1670 (USA) E-Mail saxe@berkeley.edu 
change. Others are related to how the authors measure cognitive development. And still others are related to whether their methodological approach can inform in nontrivial ways our understanding of culture-cognition relations in which cultural history is a central construct. In my comments, I reflect on some opportunities and limitations in the authors' conceptual and methodological program.

\section{Culture Change: Cross-Cultural Comparisons as a Proxy}

Gauvain and Munroe produce cross-cultural comparisons between traditional and industrial societies as a proxy for studying culture change within individual cultural groups. There is a lot to say about this technique. The advantages should be clear: if Gauvain and Munroe were to conduct a direct study of societies' changes over time within single groups, they would need a substantial time frame. Consider, for example, Schmandt-Besserat's [1992] analysis of a 5,000-year stretch of Ancient Mesopotamian history to support conjectures about the emergence of cuneiform numeracy. Or, consider Swetz's [1987] analysis of a few hundred years of the Renaissance with a focus on the shift from counting boards and Roman numerals to HinduArabic numeration. Of course, unlike Gauvain and Munroe's method, these historical studies draw upon archeological and archival records and, therefore, do not have the possibility of including direct cognitive assessments of individuals during these eras that might relate historical changes to cognitive developmental ones. So, Gauvain and Munroe's method of collapsing time through cross-cultural comparisons allows for study of cognitive processes. Nonetheless, Gauvain and Munroe's method warrants scrutiny not only for what is gained but also for what is sacrificed.

Let us consider briefly some of the assumptions used in Gauvain and Munroe's cross-cultural comparisons. Several stand out, one concerned with cross-cultural comparisons to support an analysis of historical change, another concerned with sampling, and yet another concerned with historical trajectories.

Cross-Culture Comparison Assumptions. The authors assume that cross-cultural comparisons (small-scale traditional vs. industrial) can serve as a valid proxy for societal change. The assumption carries with it a cost: it effectively removes from the analysis how individual (cognitive) activities may be implicated in the process of societal changes. It also removes from the analysis the individuals' local (cognitive) adaptations to ongoing societal shifts. This is a big sacrifice for a treatment of the relation between culture change and the cognitive development of individuals. I will return shortly to alternatives.

Sampling Assumptions. In contrasting two small-scale traditional and industrial communities, the authors are sampling from a universe of communities. Samples of two as representative must of course be suspect - does the sample capture the properties of the population of societies from which the samples were drawn to warrant statistical generalization? Of course, the study functions more as an exploration, so the assumption can be relaxed, but one does wonder about variation - to what extent are the selected societies representative of other societies, and therefore what are the generalizable implications of their findings?

234 Human Development $\quad$ Saxe


Trajectory Assumptions. In identifying a shift from small-scale traditional to large scale, the authors assume a 'standard trajectory,' reducing societal change to a single dimension. They then seek to capture ways that the proxy for historical change might be understood as affecting cognitive development by correlational analyses associated with the large-scale shift. To what extent does this trajectory assumption hold for human communities? Is this grain size useful in understanding historical change and its relation to cognitive development? Are there other ways of conceptualizing trajectories of societal change?

\section{Cognitive Development: Standardized Assessments as Measures}

Gauvain and Munroe use standardized cognitive assessments to evaluate the capacities of individuals in different cultural settings. This is a common method in cross-cultural research: the authors use the same metric to assess variation in individual performance (dependent variable) and then relate those measurements to variation in culture (independent variable). The findings do show the anticipated cultural differences in individuals' cognitive performance. That said, one may question what is revealed by these measures, and, as Gauvain and Munroe note, many scholars have raised appropriate concerns about threats to validity of findings when standard cognitive tests are used in cross-cultural studies.

In a recent article, Medin, Bennis, and Chandler [2010] sum up the problems of standardized assessments by referring to a 'home field advantage,' an advantage enjoyed by individuals schooled in industrial societies. Consider that in Gauvain and Munroe's project, IQ-like items were used to assess cognition. Various scholars have pointed out that such cognitive items were originally developed to capture the intellectual demands of classrooms [e.g., Cole, 1996; Ginsburg, 1997], and such is the home field advantage of children from industrial societies who have participated at length in such classroom worlds. This means that not only will individuals from industrial communities be more likely to perform better on such assessments (their 'home field advantage'), but also that these assessments will fail to capture the kinds of local knowledge children may be constructing in small-scale traditional societies. Indeed, the etic approach taken by Gauvain and Munroe has the virtue of rendering comparable measurements across cultures but sacrifices emic concerns [Berry \& Dasen, 1974; Harris, 1976; Pike, 1967]: the approach leaves invisible cognitive adaptations that individuals create to local conditions and that are responsive to local concerns in their 'own fields.'

\section{Culture and Cognition - Dynamic Relations through Historical Time}

Gauvain and Munroe argue for the import of a contextualist perspective to interpret their cross-cultural comparisons. They endorse ideas that culture and cognition are jointly constituted in human activity, and, perhaps, that people are producing local adaptations to solve emergent problems in cultural life. If pushed, I expect that they would agree that not only are cultural processes interwoven in the cognitive development of individuals, but also that individuals' cognitive activities (and hence developments) are part and parcel to the reproduction and alteration of cultural life, including collective representations and ideas. That said, the empirical 
project they describe in which history is a central construct is mismatched with their contextualist commitments. Indeed, their methodological approach precludes an analysis of cognitive developments as they are produced through microgenetic processes, as they are propagated through sociogenetic processes, and as they become equilibrated through ontogenetic processes, constructs that Gauvain and Munroe make reference to but that remain far from focus in their methods.

To illustrate what is lost by their empirical approach from the point of view of a developmentally oriented contextualist perspective, I draw upon some examples from my recent book, the Cultural Development of Mathematical Ideas: Papua New Guinea Studies [Saxe, 2012]. Drawing upon fieldwork conducted in 1978, 1980, and 2001 in Oksapmin communities, the book provides an analysis of culture-cognition relations with careful attention to history as a central organizing construct.

\section{Oksapmin Communities in Papua New Guinea: An Illustrative Case}

In the Gauvain and Munroe classifications, the Oksapmin would be treated as a small-scale traditional group. Western contact with the Oksapmin occurred in 1938 by the Hagen-Sepik patrol as they trekked through the rugged central highlands region of the New Guinea Island. To this day, the communities remain remote. There are still no roads to the area, and access is by small aircraft to difficult-tonavigate dirt strips. But the community is also in flux. In the early 1960s, the first mission station and patrol posts were established, and, a number of years later, the first school was established. In 2001, the time of my last field visit, economic exchange with currency had become a part of daily life.

The focus of my work in Oksapmin was mathematical cognition. Of special interest was Oksapmin people's use of indigenous representational forms, like their 27-body-part counting system (fig. 1), and the way ongoing historical changes in the way they organize their activities in collective practices of daily life are leading people to use these forms to serve new functions. To illustrate, I'll focus on two analyses. The first is about adaptations as the body system becomes used to serve newly emerging arithmetical functions in shifting collective practices associated with schooling. The second is about the emergence of a representational system for currency tokens associated with shifting collective practices associated with economic exchange. In both cases, the new developments in the community are products of cognitive work of individuals as they are accomplishing emergent goals related to collective practices.

\section{Schooling in Oksapmin}

In traditional life, arithmetical problems did not emerge for people in Oksapmin communities (at least in ways that led to arithmetical solutions), but people did use the 27-body-part counting system to serve representational functions related to number. Traditional uses of the body system included the counting of valuables, communicating about cardinal or ordinal values, or tallying contributions to bride price. Arithmetical problems emerged for people in several arenas of post-Western contact. One of these was collective practices associated with classroom life in the new bush schools. 


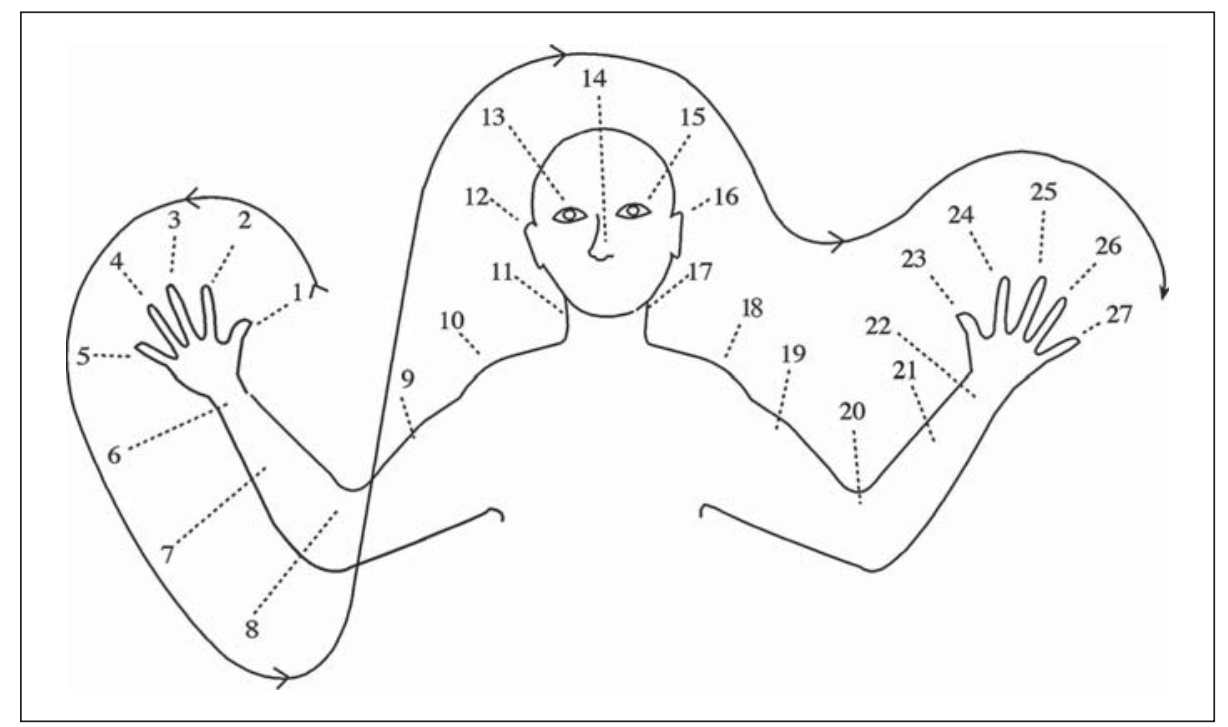

Fig. 1. The Oksapmin 27-body-part counting system [adapted from Saxe, 2012, fig. 12].

During my first two fieldtrips (in 1978 and 1980), classroom instruction was colonial in style. The Papua New Guinea educational policy was that instruction was to be in English, and that the focus of instruction should be largely on standard school subjects reflected in Western schooling (e.g., literacy, mathematics), often using drill and practice as the staple of instruction. In 1980, teachers were from more westernized parts of Papua New Guinea, and teachers' stay in Oksapmin was often short. Teachers did not know the Oksapmin language or Oksapmin practices. ${ }^{1}$ Teachers lived on the school grounds and were separate from the community.

In 1980, I observed an interesting sight. Children were working at their seats and pointing around their bodies as they solved addition and subtraction problems. I queried teachers about the pointing, but they had little to say about it; they were focused on the lessons. In fact, teachers did not know the body system or of it.

The observations led to several studies. In a first study, I documented the extent of children's use of the system while taking a test, showing that many of the children were pointing as they solved the problems (fig. 2).

In a second study, I interviewed children about their body strategies. To determine whether schooled children's body strategies could be attributed to participation in school, I contrasted schooled children's performances with unschooled adolescents' performances (also obtained through interview) from the same communities. The findings of the interview studies illustrate the way new collective practices can

\footnotetext{
${ }^{1}$ For many teachers, Oksapmin was an undesirable assignment because it was a remote area, known for warfare with neighboring groups, and lacked modern amenities, like electricity, running water, etc.
} 


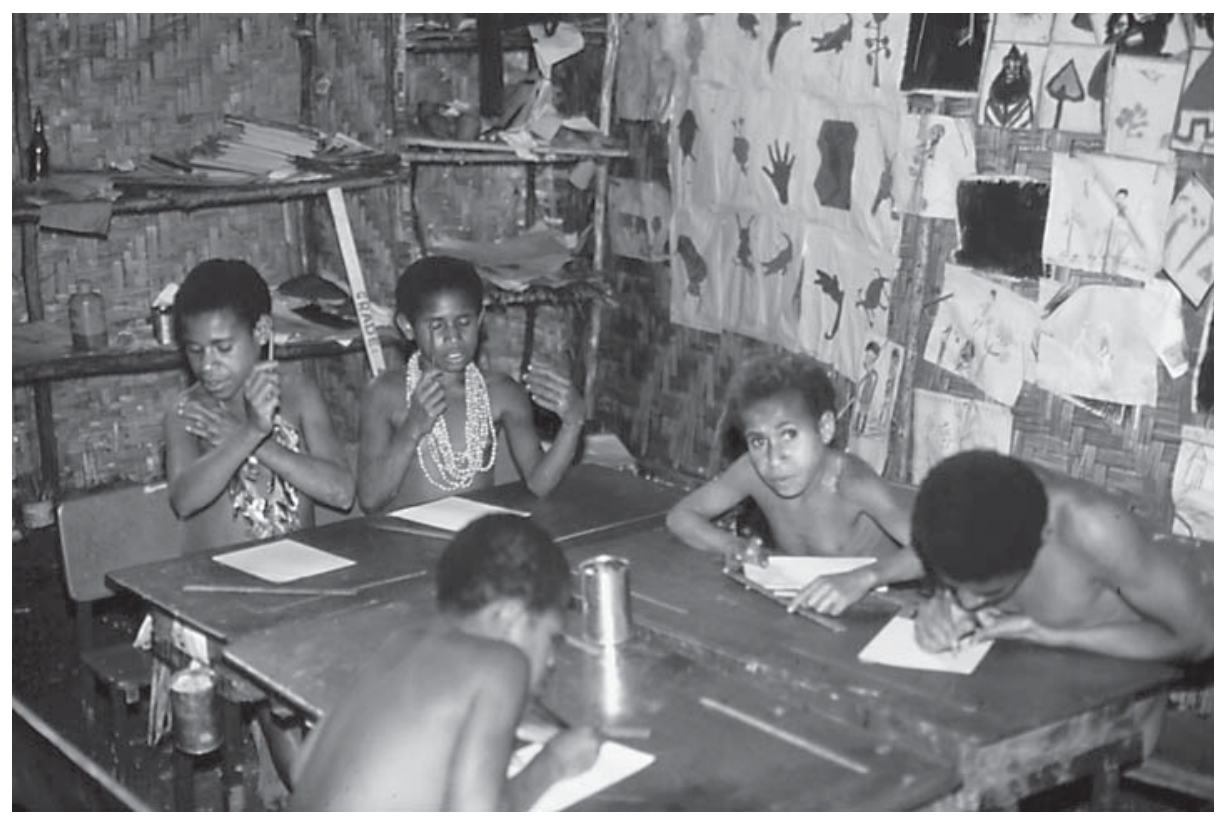

Fig. 2. Grade 4 children counting around their bodies during an arithmetic test [from Saxe, 2012, fig. 97].
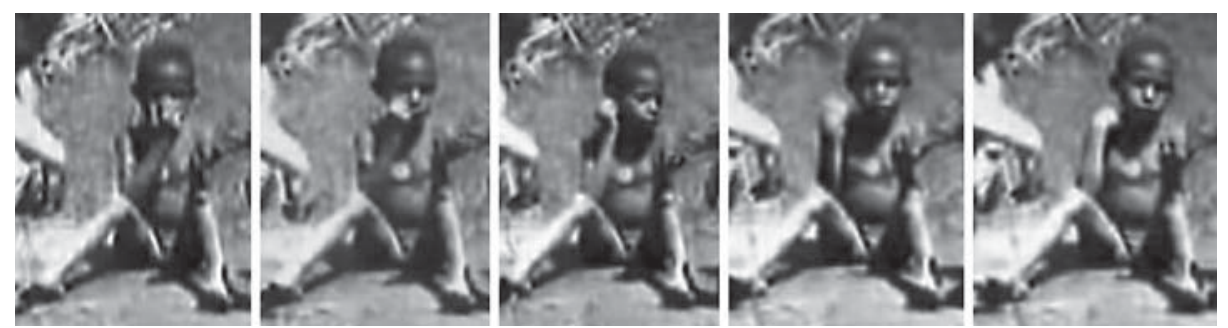

Fig. 3. A child using a double enumeration procedure, creating a one-to-one correspondence between two body part series as he keeps track of the subtraction of one term from another [from Saxe, 2012, fig. 98]. Note: a video from which images were extracted can be found at: http://www. culturecognition.com/fourth-grader-solving-16-7-body-system/.

lead individuals to repurpose cultural forms to serve new functions, cognitive developments inherently linked to historical changes. Unschooled children used their bodies to represent addition and subtraction problems. However, they did not create adequate ways to accomplish the addition or subtraction of values. Such a feat would require a way of keeping track of the act of adding one body part series to another, or of subtracting one series from another. In contrast, school children (grade 4 and grade 6) often created strategies that coordinated two body part series. For example, figure 3 illustrates a fourth grader solving the problem $16-7=$ ? and figure 4 shows a 


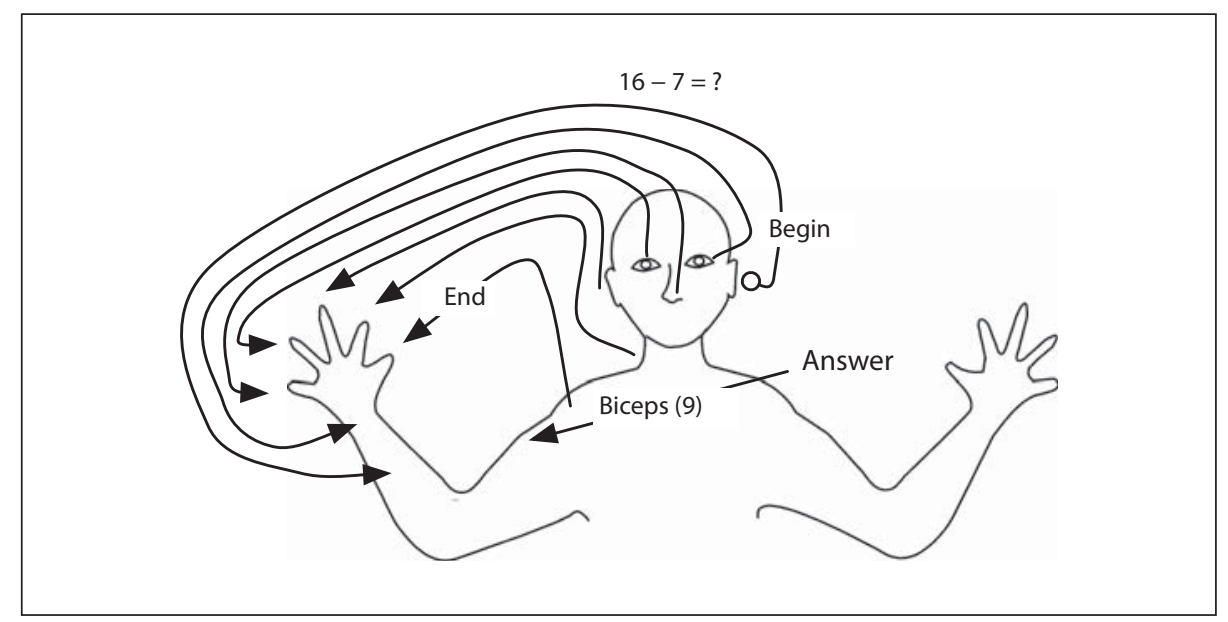

Fig. 4. A double enumeration strategy used to solve the problem $16-7=$ ? [from Saxe, 2012, fig. 36b].

schematic of the fourth grader's strategy. The child begins by first representing 16 as 'ear on the other side' (16). The subtraction of 7 is achieved by counting down on the body. In this process, the child coordinates two series to keep track of the subtraction. The child establishes correspondences between the following pairs of body parts: (a) the ear on the other side (16) and the forearm (7), (b) the eye on the other side (15) and the wrist (6), (c) nose (14) and pinky (5), (d) eye (13) and ring finger (4), (e) ear (12) and middle finger (3), (f) neck (11) and index finger (2), and (g) shoulder (10) and thumb (1). The next body part is the biceps (9), which was his solution.

Noteworthy is that these strategies were not taught by teachers; they were students' own constructions as they engaged with new kinds of problems related to collective practices of classroom life. In an important sense, the strategies reflect microgenetic constructions as children adapt the body system to serve new functions in classroom life. The strategies also reflect ontogenetic developments in the cognitive functioning of children and, importantly, sociogenetic developments in the history of the body system in Oksapmin communities. Such multileveled genetic processes and their occurrence in shifting collective practices would be invisible in cross-cultural comparisons using standard measures.

Like Gauvain and Munroe's approach, the method used in these 1980 Oksapmin studies on schooling functioned to 'collapse time' through a comparison of participants on cognitive tasks. But unlike Gauvain and Munroe's cross-cultural comparison (small-scale traditional vs. industrial societies compared on standardized assessments), in the Oksapmin case, the method was intracultural and situated in collective practices. ${ }^{2}$ It began with observation, moved to an observational study, and culminated with interview studies that compared schooled and nonschooled children on a targeted set of tasks related to the observations.

\footnotetext{
${ }^{2}$ Other exemplars of intracultural approaches to the study of culture-cognition relations through time include the work of Greenfield [2004], Luria [1976], Rogoff [2011], and Scribner \& Cole [1981].
} 


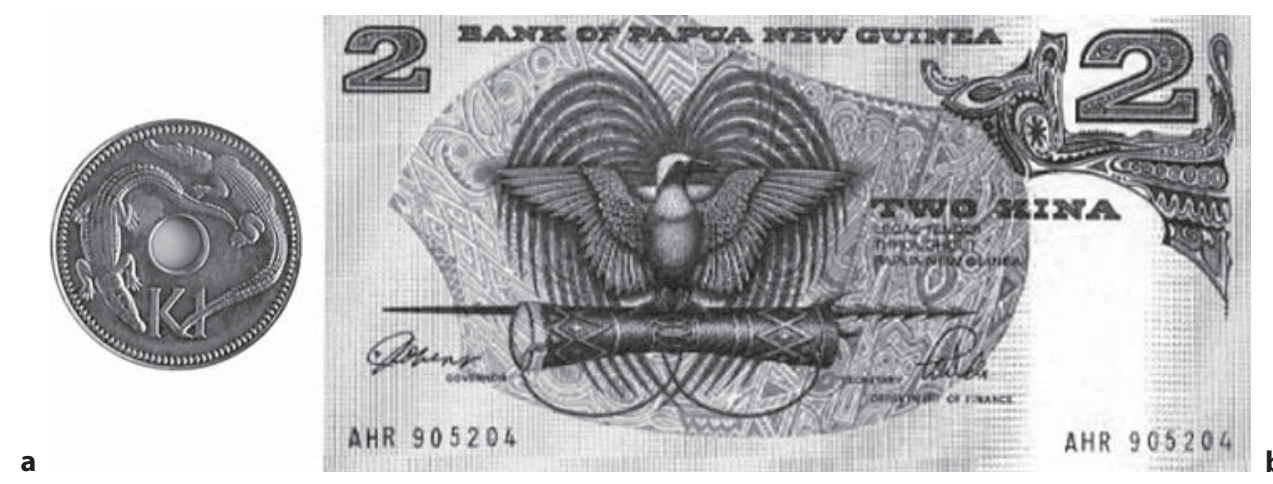

Fig. 5. a A one-kina coin (represented in the Oksapmin lanaguage as 'flat with hole'). b A 2-kina note (represented in the Oksapmin language as 'leaf').

\section{Economic Exchange in Oksapmin}

A second illustration comes from collective practices associated with economic exchange. In 2001, when people named currency tokens in the Oksapmin language, their names often captured physical properties of the tokens themselves. For example, people often called the one-kina coin shown in figure $5 \mathrm{a}$ temsi-tana or 'flat with hole,' and the two-kina note in figure $5 \mathrm{~b}$ haben or 'leaf'. In developmental formulations, such motivated relations between names for things and the things to which the names refer were considered to index a lower level of cognitive functioning than representations that make use of arbitrary relations between symbolic vehicles and referential objects [Piaget, 1962, 1979; Vygotsky, 1986; Werner \& Kaplan, 1963]. But from a historical perspective, one may well be led to a different path of conjectures and corroboration.

To understand the numerical properties of people's representation of currency tokens, my graduate students and I presented Oksapmin people with tasks that required them to sum tokens, like one 5-kina and three 2-kina notes depicted in figure 6. People often summed the values appropriately. Importantly, in their solutions, word forms like temsi did not refer to the physical features of the tokens but instead were used numerically. For example, a common solution to the summation problem in figure 6 was hanen fu tit temsi tit, which literally translated means something like 'five doubled (10) once hole (1) once,' or 11 kina. But note that there is no 'flat with hole' in the material tokens summed - only notes of two kina and five kina (fig. 6). Thus, such constructions show that the use of 'hole' is not concrete at all; rather it refers to a numerical value of one kina, which can be composed (and decomposed) in arithmetical operations with other numerical values.

In the research on naming practices just described, I documented two cognitive adaptations in the recent cultural history of the community: (a) the early repurposing of words to name currency tokens (like temsi [hole] to refer to the one-kina coin), and (b) the subsequent construction of numerical functions for these token names (like the use of temsi to refer to the value of one kina in arithmetical compositions). How might such collective representations for naming tokens emerge and shift in the 

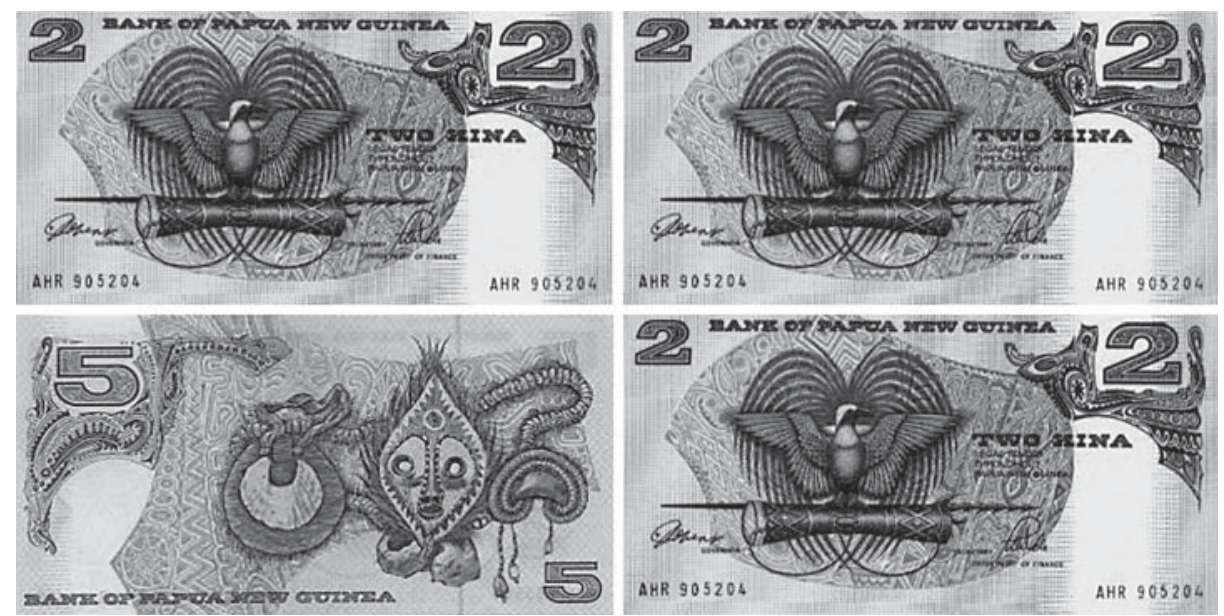

Fig. 6. Currency tokens presented in a token summation task: three 2-kina notes and one 5-kina note [adapted from Saxe, 2012, fig. 67].

history of a group? Consider a process model that I elaborate in Cultural Development of Mathematical Ideas. Imagine situations early in the introduction of currency tokens in which tokens had no names in the Oksapmin language, but interlocutors were engaged in referencing them in interactions. One sensible approach would be to signal to another the token referred to by its physical characteristics, like 'flat with hole' or leaf (fig. 5). Here, the idea would be that each interlocutor is familiar with properties of holes and leaves and that these terms can orient the other to the items referred to in appropriate communicative contexts. Imagine also that there are many interlocutors at varied sites, say at many different trade posts in Oksapmin, with each trying to communicate his or her intended meanings to others. Some perhaps use temsi, others use hardness, others use emblems on the coins themselves, etc. Through (historical) time, people reuse what they think will orient the other to their communicative intents in their choices of word forms. To do this, they draw on precedent, what worked previously in prior interactions. Through such a process, through time, semi-stable representational systems emerge. Of course, in this process, there may also be problem-solving functions that emerge for these emerging representational forms, and thus the forms may take on numerical as well as communicative functions.

In their empirical project with the late Ruth Munroe, Gauvain and Munroe extend a tradition in the behavioral sciences that, for analytic purposes, reduces culture to categories of small-scale traditional or industrial and, likewise, cognition to performance on IQ-like measures. Gauvain and Munroe extend the tradition in sensible ways by identifying factors that may be mediating the documented associations between culture and cognition. A key advantage of this approach for investigation into societal change and cognitive development is that it allows for investigators to collapse time and, thereby, study cognitive achievements of individuals' functioning in what are proxies for different historical periods. Gauvain and Munroe's focus on 
various factors that may be mediating these cross-cultural effects moves this effort forward in helpful ways.

A key concern of mine is what is rendered invisible in the methodological approach: the dynamic interplay between individual and collective activity through historical time that leads to the reproduction and alteration of collective representations and ideas. Developing conceptual and methodological models to capture such processes would provide avenues not only for understanding people's role in reproducing and altering cultural life through historical time, but also for understanding the role of collective life in framing cognitive developments of individuals. In my read, these concerns are consistent with some of the contextualist and developmental directions of the article, but that thinking seems out of touch with the authors' empirical project.

\section{References}

Berry, J.W., \& Dasen, P.R. (1974). Introduction. In J.W. Berry \& P.R. Dasen (Eds.), Culture and cognition: Readings in cross-cultural psychology (pp. 16-17). London: Butler \& Tanner Ltd.

Cole, M. (1996). Cultural psychology: A once and future discipline? Cambridge: Harvard University Press.

Gauvain, M., \& Munroe, R.L. (2009). Contributions of societal modernity to cognitive development: A comparison of four cultures. Child Development, 80, 1628-1642.

Ginsburg, H.P. (1997). Entering the child's mind: The clinical interview in psychological research and practice. New York: Cambridge University Press.

Greenfield, P.M. (2004). Weaving generations together: Evolving creativity in the Maya of Chiapas (1st ed.). Santa Fe: School of American Research Press.

Harris, M. (1976). History and significance of the emic/etic distinction. Annual Review of Anthropology, $5,329-350$.

Luria, A.R. (1976). Cognitive development: Its cultural and social foundations. Cambridge: Harvard University Press.

Medin, D., Bennis, W., \& Chandler, M. (2010). Culture and the home-field disadvantage. Perspectives on Psychological Science, 5, 708-713.

Piaget, J. (1962). Play, dreams, and imitation in childhood (C. Gattegno \& F.M. Hodgson, Trans.). New York: W.W. Norton \& Company, Inc.

Piaget, J. (1979). The child's conception of the world (J. Tomlinson \& A. Tomlinson, Trans.). Totowa: Littlefield, Adams \& Co.

Pike, K.L. (1967). Language in relation to a unified theory of structure of human behavior (2nd ed.). The Hague: Mouton.

Rogoff, B. (2011). Developing destinies: A Mayan midwife and town. New York: Oxford University Press. Saxe, G.B. (2012). Cultural development of mathematical ideas. New York: Cambridge University Press. Schmandt-Besserat, D. (1992). Before writing. Austin: University of Texas Press.

Scribner, S., \& Cole, M. (1981). The psychology of literacy. Cambridge: Harvard University Press.

Swetz, F. (1987). Capitalism and arithmetic: The new math of the 15th century, including the full text of the Treviso arithmetic of 1478, translated by David Eugene Smith. La Salle: Open Court.

Vygotsky, L.S. (1986). Thought and language. Cambridge: MIT Press.

Werner, H., \& Kaplan, B. (1963). Symbol formation: An organismic-developmental approach to language and the expression of thought. New York: Wiley. 